\title{
Distortion Elimination for Buck PFC Converter with Power Factor Improvement
}

\author{
Jiangtao $\mathrm{Xu}^{\dagger}$, Meng Zhu*, and Suying Yao* \\ ${ }^{*}$ School of Electronic Information Engineering, Tianjin University, Tianjin, China
}

\begin{abstract}
A quasi-constant on-time controlled buck front end in combined discontinuous conduction mode and boundary conduction mode is proposed to improve power factor (PF).When instantaneous AC input voltage is lower than the output bus voltage per period, the buck converter turns into buck-boost converter with the addition of a level comparator to compare input voltage and output voltage. The gate drive voltage is provided by an additional oscillator during distortion time to eliminate the cross-over distortion of the input current. This high PF comes from the avoidance of the input current distortion, thereby enabling energy to be delivered constantly. This paper presents a series analysis of controlling techniques and efficiency, PF, and total harmonic distortion. A comparison in terms of efficiency and PF between the proposed converter and a previous work is performed. The specifications of the converter include the following: input $\mathrm{AC}$ voltage is from $90 \mathrm{~V}$ to $264 \mathrm{~V}$, output $\mathrm{DC}$ voltage is $80 \mathrm{~V}$, and output power is $94 \mathrm{~W}$. This converter can achieve PF of $98.74 \%$ and efficiency of $97.21 \%$ in $220 \mathrm{~V}$ AC input voltage process.
\end{abstract}

Key words: AC-DC converter, Buck, Power factor correction, Pulse assisting technique

\section{INTRODUCTION}

Power quality has become an important consideration in power systems. Thus, much attention has been given to converters with high power factor (PF), low input harmonics, and good efficiency [1]-[3]. Power factor correction (PFC) provides many attractive benefits, including automatic line-voltage adjustments, nearly sinusoidal input current, and improved power quality. PFC front ends are now commonly used in power supply systems, which are connected to an AC line. This $\mathrm{AC}$ line ensures that power equipment are in accordance with many standards, such as IEC61000-3-2 specification [4], which is used to limit harmonic current; European Code of Conduct specifications [5], which defines the minimum average efficiency of external power supplies at $25 \%, 50 \%, 75 \%$, and $100 \%$ of full load; and Energy Star [6], which sets the minimum limit at $0.9 \mathrm{PF}$.

In a step-down situation, one approach is two-stage converter: boost PFC front end [7], [8] combined with buck DC-DC downstream. PFC circuit is employed to obtain the

Manuscript received May 21, 2014; accepted Jul. 31, 2014

Recommended for publication by Associate Editor Honnyong Cha.

${ }^{\dagger}$ Corresponding Author: xujiangtao@tju.edu.cn

Tel: + 86-022-27408966, Fax: + 86-13752356309, Tianjin University

*School of Electronic Information Eng., Tianjin University, China sinusoidal input current to provide a high $\mathrm{PF}$, whereas the DC-DC converter is used to regulate the output voltage. However, this structure has the disadvantages of low power density, high control complexity, and high cost because it includes additional PFC circuit. Single-stage [9]-[11] AC-DC converters have received much attention because of their cost effectiveness, compact size, and simple control mechanism. Another approach is buck-boost topologies, such as general buck-boost converter, fly-back converter [12], single-ended primary inductance converter (SEPIC), and Ćuk converter, which could act as step-down transformers [13]. In particular, SEPIC converter can achieve high PF and reduce output voltage stress. However, the voltage stress of switch is still relatively high. In addition, the efficiency decreases, and the cost increases.

Although buck converters are not widely used, these converters can also be used as a PFC front end [14]-[17]. Buck converter maintains high efficiency because of low average input current and root mean square (RMS) current at low input voltage. However, a buck PFC converter has difficulty achieving high $\mathrm{PF}$ because of its crossover distortion of input current when the input voltage is lower than output voltage. Moreover, the occurrence of input current distortion promotes total harmonic distortions (THD). Conventional buck PFC converter has difficulty passingIEC61000-3-2 standards 
because of THD

An effective method to improve PF of the buck PFC converter is to modify the structure. Two step-down converters are proposed in [18], which include an auxiliary fly-back stage. The stage uses the same switch as a buck converter, and an additional power switch is commutated at the line frequency. The distortion of the input current can be eliminated with auxiliary fly-back converter. However, an additional diode that leads to additional losses is inserted in the power loop when these two topologies operate in buck mode. The interleaved power converter that operates at the boundary conduction mode (BCM), which is proposed in [19], can be used to recover the distortion of input current. However, the additional coupled inductor complicates the structure, which makes this structure unsuitable for such an arrangement.

In this study, a pulse-assisting buck (PAB) PFC converter is designed. The envelope of input current of the proposed buck converter is quasi-sinusoidal when buck-boost topology is turned in discontinuous mode where the drive signal is provided by additional pulse during distortion time. The predominant drawback of buck PFC can be overcome by adding discontinuous conduction mode (DCM) operation during the distortion time to make the current continuous. The DCM operation of all single-switch topologies is most suitable for low-power applications [20]. The proposed PAB converter is suitable for step-down PFC front end of an AC-DC converter.

The detailed operation principle is illustrated in Section II, the circuit parameters design considerations are presented in Section III, and the results based on a $94 \mathrm{~W}$ prototype are shown in Section IV. A conclusion is presented in Section V.

\section{OPERATION PRINCIPLE}

The output bus voltage of a conventional buck converter that is connected to a $50 \mathrm{HzACsource}$ and bridge rectifier is set at a level less than the peak AC voltage at the lowest line voltage. When the instantaneous $\mathrm{AC}$ input voltage is greater than the output bus voltage, the PFC stage is forward biased, and the current can be drawn from the $\mathrm{AC}$ input. However, when the instantaneous $\mathrm{AC}$ input voltage falls below the bus voltage level, the diode bridge rectifiers become reverse biased, and no power can be drawn from the AC line. This condition is called crossover distortion of the input current, as shown in Fig. 1. The conduction angle can be calculated from (1).

$$
t_{1}=\frac{1}{100 \pi} \arcsin \frac{V_{\mathrm{o}}}{V_{\mathrm{in}}}, t_{2}=0.01-t_{1} .
$$

\section{A. Preliminary}

For the proposed $\mathrm{PAB}$ converter, the $\mathrm{PAB}$ converter operates in $\mathrm{BCM}$, which is same as the conventional buck converter, when the instantaneous $\mathrm{AC}$ input voltage is higher

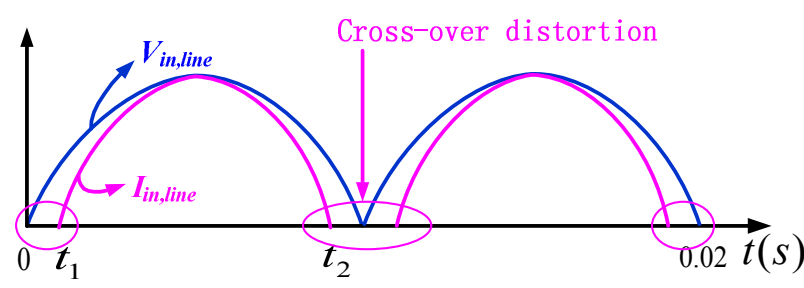

Fig. 1. Crossover distortion of the input current.

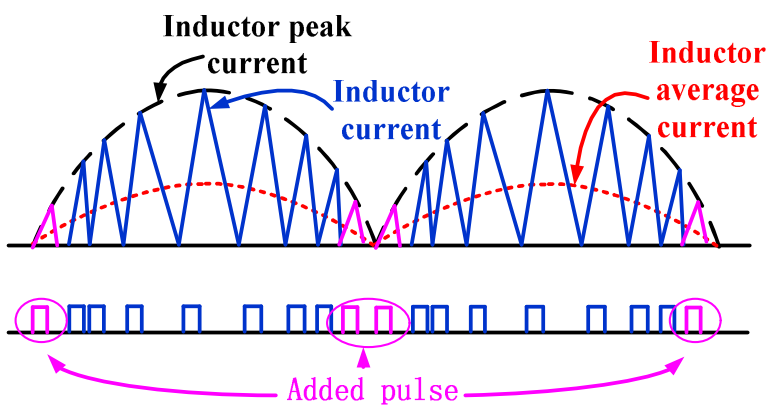

Fig. 2. Current waveform of the proposed converter.

than the output voltage [22]. When the input voltage is lower than the output voltage, the PAB converter operates in DCM, in which the gate drive voltage is provided by the PFC controller. Hence, the PF can be improved obviously and THD can be substantially eliminated based on preserving the merits of the conventional buck converter.

The current waveforms of the PAB converter are shown in Fig. 2. When the PAB buck converter operates in BCM, the positive edge of gate drive voltage is determined by zero current detection (ZCD) of the inductor current. When the converter operates in DCM during the distortion time, the turn-on instant is determined by the internal oscillator of PFC controller. The conduction of switch Q1 and Q2 in Fig. 3 is initiated by the oscillator of the controller in every beginning of a period.

\section{B. Working Process}

The converter operates in several stages during a sinusoidal period, as shown in Fig. 4.

1) DCM: When the magnitude of input voltage $\mathrm{V}_{\text {in }}$ is smaller than the output voltage $\mathrm{V}_{\mathrm{o}}$, the proposed converter operates in DCM. The switches Q1 and Q2 are switched on and off synchronously and controlled by internal pulse.

When Q1 and Q2 turn on, the proposed converter operates in Stage 1. The equivalent circuit is illustrated in Fig. 4(a). In this stage, inductor $\mathrm{L}$ is charged by $V_{\text {in }}$, and inductive current $i_{\mathrm{L}}$ increases during this stage.

When Q1 and Q2 turn off, the proposed converter operates in Stage 2. The equivalent circuit is illustrated in Fig. 4(b). In this stage, inductor $\mathrm{L}$ is discharged by $V_{\mathrm{o}}$, and $i_{\mathrm{L}}$ decreases during this stage.

2) BCM: When the magnitude of $\mathrm{V}_{\text {in }}$ is greater than $V_{o}$, the proposed converter operates in BCM. The switch Q2 remains 


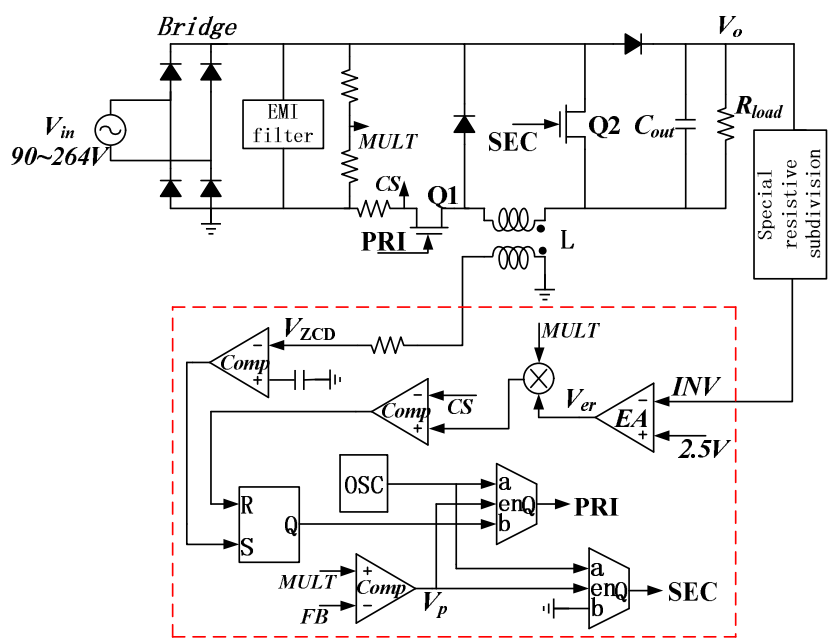

Fig. 3. Schematic of the PAB converter and its controller.

switched off, and switch Q1 is controlled by signal PRI by the PFC controller.

When Q1turns on, the proposed converter operates in Stage 3. The equivalent circuit is illustrated in Fig. 4(c). In this stage, inductor $\mathrm{L}$ is charged by $V_{\text {in }}-V_{\mathrm{o}}$, and $i_{\mathrm{L}}$ increases during this stage.

When Q1turns off, the proposed converter operates in Stage 4. The equivalent circuit is illustrated in Fig. 4(d). In this stage, inductor $\mathrm{L}$ is discharged by $V_{\mathrm{o}}$, and $i_{\mathrm{L}}$ decreases during this stage.

Based on the preceding analysis, the PFC controller is designed as shown in Fig. 3.

The input voltage $V_{\text {in }}$ is detected and divided to obtain a signal MULT. Similarly, the output voltage $V_{\mathrm{o}}$ is represented by $F B$ with the same ratio as that of MULT representing $V_{\text {in }}$. Then, the control signal $V_{\mathrm{p}}$ can be calculated by comparing MULT and $F B$. The signal $V_{\mathrm{p}}$ is high logic when MULT is higher than $F B$ and is low logic when $M U L T$ is lower than $F B$. The control signal $V_{\mathrm{p}}$ is used to determine whether the converter operates in DCM or BCM.

The detected output signal $I N V$ is sent to the negative input of the error amplifier. The error between $I N V$ and the set reference voltage $V_{\text {ref }}$ is amplified by the compensation networks, and then the amplified error signal $V_{\mathrm{er}}$ is achieved. The DC voltage signal $V_{\text {er }}$ is applied to one input port of the multiplier, whereas another input signal of the multiplier is MULT. The waveform envelope of the output of the multiplier is a rectified sine wave. The output of the multiplier is used as a reference signal of the current comparator, and the output of the current comparator is used to control the peak current per cycle of the switch. When the voltage of the buck inductor is reversed, ZCD module opens the external switch. Thus, the circuit operates in BCM.

Two of the input signals of the selectors are the internal pulse and the output of the RS trigger, whereas other input signals of the selectors are the internal pulse and ground. The

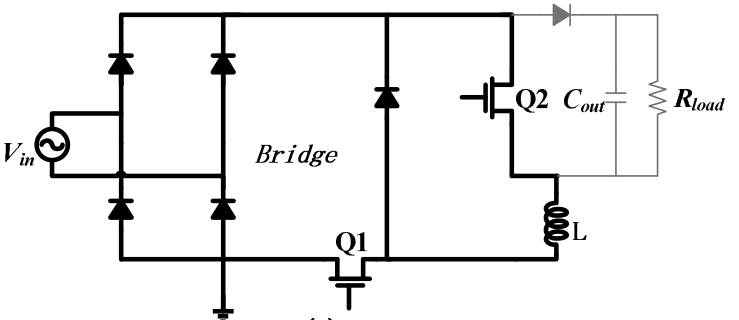

(a)

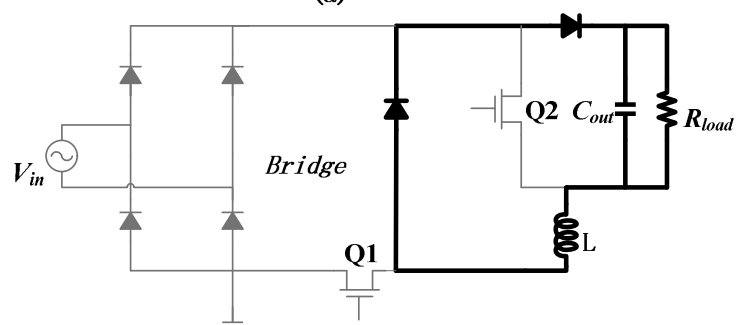

(b)

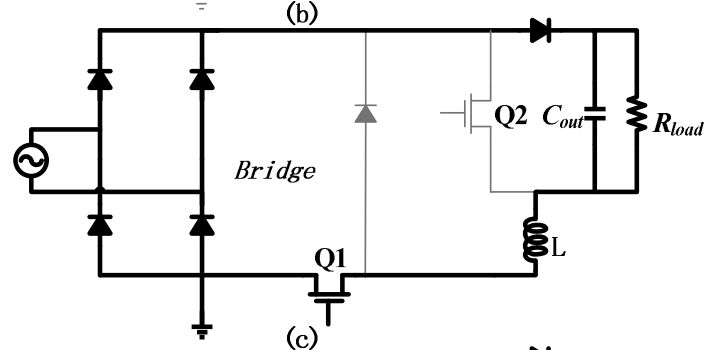

(c)

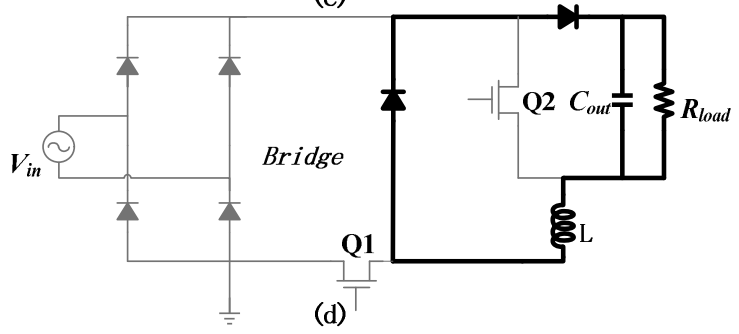

Fig. 4. Operating stages of the PAB converter.

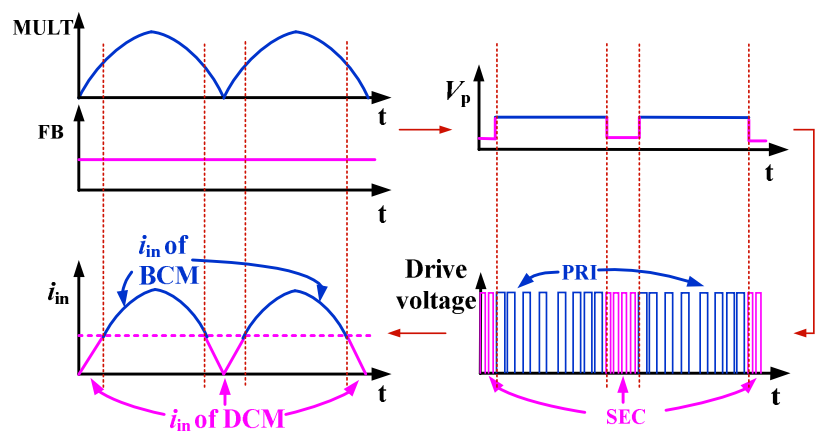

Fig. 5. Key waveforms of nodes $M U L T, F B, V_{\mathrm{p}}, P R I$, and $S E C$ and $i_{\text {in }}$ PAB converter.

output signals $P R I$ and $S E C$ of the two selectors are the gate signal of Q1 and Q2, respectively.

The PAB converter operates in DCM controlled by an internal oscillator. The frequency of the internal pulse is $f_{\mathrm{s}}$, and the duty cycle is $D_{0}$ during distortion time. The PAB converter operates in boundary mode during conduction time by using constant on-time (COT) control. The waveforms of 
nodes MULT, FB, $V_{\mathrm{p}}, P R I$, and $S E C$ and of input current $i_{\text {in }}$ are shown in Fig. 5.

The signal $V_{\mathrm{p}}$ determines different operation modes alternately per cycle by controlling the gate signals $P R I$ and $S E C$. Different frequencies $f_{\mathrm{s}}$ of internal pulse result in the different performances of the PAB converter. The detailed optimization of frequency $f_{\mathrm{s}}$ and duty cycle $D_{0}$ during the distortion time is presented in Section III.

\section{ANALYSIS OF THE PAB CONVERTER}

Design considerations of the PAB converter controlled by the proposed PFC controller are presented in this section. All the calculations are based on a $94 \mathrm{Wprototypewith} 90 \mathrm{~V}$ to $264 \mathrm{~V}$ universal AC input. The output voltage is set to $80 \mathrm{~V}$. The circuit described in this paper can easily obtain high PF. The following are the analyses of the input current and how the frequency and the duty cycle of internal pulse during the distortion time affect the performance of the circuit.

\section{A. Current Analysis}

According to the operating stage analysis shown in Fig.3, the characteristics of the PAB PFC converter can be derived. When the input voltage is lower than the output voltage in a half line cycle, the converter is equal to a DCM buck-boost converter. When the input voltage is higher than the output voltage, the $\mathrm{PAB}$ converter works like a BCM conventional buck converter. The input current in the half line cycle can be described as follows, whereas the conduct angle can be calculated from (1)

$$
i_{i n}=\left\{\begin{array}{lr}
D_{B C M} \cdot \frac{i_{p k, B C M}}{2}, & t_{1}<t<t_{2} \\
D_{D C M} \cdot \frac{i_{p k, D C M}}{2}, & \left(0<t<t_{1}\right) \text { and }\left(t_{2}<t<0.01\right)
\end{array} .\right.
$$

where $D_{\mathrm{BCM}}$ and $D_{\mathrm{DCM}}$ are duty cycles in BCM and DCM, respectively. The peak value of the input current is $i_{\mathrm{pk}, \mathrm{BCM}}$ and $i_{\mathrm{pk}, \mathrm{DCM}}$ in BCM and DCM, respectively.

$$
\begin{gathered}
D_{B C M}=\frac{V_{o}}{V_{i n} \cdot \sin (100 \pi \cdot t)}, \quad D_{D C M}=D_{0} . \\
i_{p k, B C M}=\frac{V_{i n} \cdot \sin (100 \pi \cdot t)-V_{0}}{L} \cdot t_{o n}, \\
i_{p k, D C M}=\frac{V_{i n} \cdot \sin (100 \pi \cdot t) \cdot D_{0}}{L \cdot f_{s}} .
\end{gathered}
$$

The following is the final expression of the input current obtained by substituting (3) and (4) into (2):

$$
i_{i n}=\left\{\begin{array}{l}
\frac{V_{o}}{V_{\text {in }} \cdot \sin (100 \pi \cdot t)} \cdot \frac{V_{\text {in }} \cdot \sin (100 \pi \cdot t)-V_{o}}{2 \cdot L} \cdot t_{o n}, t_{1}<t<t_{2} \\
V_{\text {in }} \cdot \sin (100 \pi \cdot t) \cdot \frac{D_{0}{ }^{2}}{2 \cdot L \cdot f_{s}},\left(0<t<t_{1}\right) \text { and }\left(t_{2}<t<0.01\right)
\end{array} .\right.
$$

where $t_{\text {on }}$ is the on-time of the primary switchQ2, which is nearly constant during the half line cycle. We introduce a factor, and replace $D_{0}^{2} / f_{\mathrm{s}}$ by $k^{*} t_{\text {on }}$ to simplify the calculation.

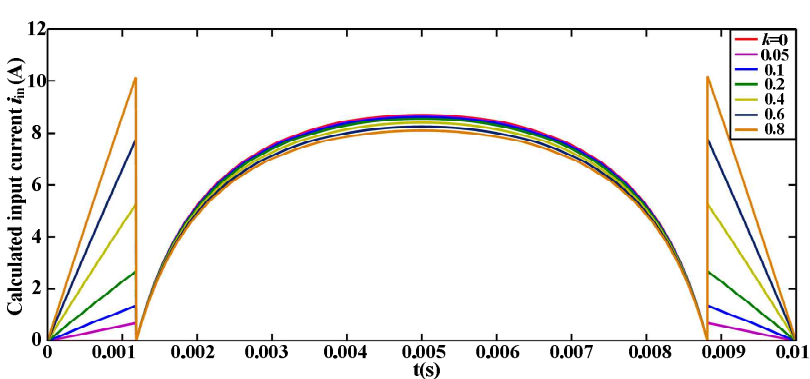

Fig. 6. Calculated input current with different factor $k$ at $220 \mathrm{~V}$ $\mathrm{AC}$ input.

We rewrite the expression of the input current as follows:

$i_{\text {in }}=\left\{\begin{array}{l}\frac{V_{o}}{V_{\text {in }} \cdot \sin (100 \pi \cdot t)} \cdot \frac{V_{\text {in }} \cdot \sin (100 \pi \cdot t)-V_{o}}{2 \cdot L} \cdot t_{\text {on }}, t_{1}<t<t_{2} \\ V_{\text {in }} \cdot \sin (100 \pi \cdot t) \cdot \frac{k \cdot t_{\text {on }}}{2 \cdot L},\left(0<t<t_{1}\right) \text { and }\left(t_{2}<t<0.01\right)\end{array}\right.$.

According to the law of energy conservation, we can obtain the equation as follows:

$$
\begin{aligned}
& \left(\int_{0}^{t_{1}} \frac{\left(V_{\text {in }} \cdot \sin (100 \pi \cdot t)\right)^{2} \cdot k \cdot t_{o n}}{2 \cdot L} d t\right. \\
& \left.+\int_{t_{1}}^{0.005} \frac{V_{o} \cdot\left(V_{\text {in }} \cdot \sin (100 \pi \cdot t)-V_{o}\right) \cdot t_{o n}}{2 \cdot L} d t\right) \cdot \eta=0.005 \cdot P_{o} .
\end{aligned}
$$

where $t_{\mathrm{on}}$ can be achieved as follows:

$$
\begin{aligned}
& t_{\text {on }}=\frac{0.01 \cdot P_{o}}{\eta} /\left(k \cdot \int_{0}^{t_{1}} \frac{\left(V_{\text {in }} \cdot \sin (100 \pi \cdot t)\right)^{2}}{L} d t\right. \\
& \left.+\int_{t_{1}}^{0.005} \frac{V_{o} \cdot\left(V_{\text {in }} \cdot \sin (100 \pi \cdot t)-V_{o}\right)}{L} d t\right) .
\end{aligned}
$$

Moreover,

$$
\begin{aligned}
& k=\left(\frac{106 \cdot 0.01}{t_{o n}}-\int_{t_{1}}^{0.005} \frac{\left(V_{\text {in }} \cdot \sin (100 \pi \cdot t)-V_{o}\right) \cdot V_{o}}{L} d t\right) \\
& / \int_{0}^{t_{1}} \frac{\left(V_{\text {in }} \cdot \sin (100 \pi \cdot t)\right)^{2}}{L} d t .
\end{aligned}
$$

According to (6), the calculated input current in one cycle with different factor $k$ at $220 \mathrm{~V}$ AC input level is shown in Fig. 6. The results and discussion are shown in Section IV.

The preceding analysis indicates that the input current varies from different $k$ and only the coefficient $k$ in a certain range could enable the converter to meet the requirements. These conditions occur because the coefficient $k$ is the function of $D_{0}$ and $f_{\mathrm{s}}$. The selection of $D_{0}$ and $f_{\mathrm{s}}$ is analyzed in the next section.

\section{B. PF Analysis and THD Analysis}

A converter that maintains PF for over 0.9 must be designed in the same way as Energy Star does, which introduces a PF legislation of 0.9 at full load. From the preceding calculation, we can obtain the expression of $\mathrm{PF}$ as follows: 
TABLE I

CALCUlated PF AND THD versus $k$ AT $V_{\text {in }}=220 \mathrm{~V}$ AC INPUT COMPARED WITH IEC61000

\begin{tabular}{cccc}
\hline \hline$k$ & PF & THD & MEET IEEE61000 \\
\hline 0.02 & 0.9831 & 0.1861 & YES \\
0.04 & 0.9847 & 0.1769 & YES \\
0.06 & 0.9861 & 0.1683 & YES \\
0.08 & 0.9874 & 0.1601 & YES \\
0.1 & 0.9885 & 0.1527 & YES \\
0.2 & 0.9918 & 0.1286 & YES \\
0.4 & 0.9873 & 0.1608 & YES \\
0.6 & 0.9699 & 0.2511 & YES \\
0.9 & 0.9265 & 0.4062 & NO \\
1 & 0.9091 & 0.4582 & NO \\
\hline \hline \multicolumn{5}{c}{$P F=\frac{P_{i}}{V_{i n} \cdot i_{r m s}}$} \\
\end{tabular}

where $i_{\text {rms }}$ is the RMS value of the input current that can be achieved as follows:

$$
\begin{aligned}
& i_{r m s}=\left(\frac{2}{0.01} \int_{0}^{t_{1}}\left(\frac{V_{\text {in }} \cdot \sin (100 \pi \cdot t)}{2 \cdot L} \cdot k \cdot t_{o n}\right)^{2} d t\right. \\
& \left.+\frac{1}{0.01} \int_{t_{1}}^{t_{2}}\left(\frac{V_{o} \cdot V_{\text {in }} \cdot \sin (100 \pi \cdot t)-V_{o}}{V_{\text {in }} \cdot \sin (100 \pi \cdot t) \cdot 2 \cdot L} \cdot t_{o n}\right)^{2} d t\right)^{1 / 2} .
\end{aligned}
$$

Moreover, $P_{\mathrm{i}}$ is the input power in a cycle

$$
\begin{aligned}
& P_{i}=\frac{1}{0.01} \cdot\left(2 \cdot \int_{0}^{t_{1}} \frac{\left(V_{i n} \cdot \sin (100 \pi \cdot t)\right)^{2}}{2 \cdot L} \cdot k \cdot t_{o n} d t\right. \\
& \left.+\int_{t_{1}}^{t_{2}} \frac{V_{o} \cdot\left(V_{i n} \cdot \sin (100 \pi \cdot t)-V_{o}\right)}{2 \cdot L} \cdot t_{o n} d t\right) .
\end{aligned}
$$

The following expression of PF and THD are obtained by substituting (11) and (12) into (10):

$$
\begin{aligned}
& P F=\frac{1}{0.01} \cdot\left(2 \cdot \int_{0}^{t_{1}} \frac{\left(V_{\text {in }} \cdot \sin (100 \pi \cdot t)\right)^{2}}{2 \cdot L} \cdot k \cdot t_{o n} d t\right. \\
&\left.+\int_{t_{1}}^{t_{2}} \frac{V_{o} \cdot\left(V_{i n} \cdot \sin (100 \pi \cdot t)-V_{o}\right)}{2 \cdot L} \cdot t_{o n} d t\right) / V_{\text {in }} \\
& /\left(\frac{2}{0.01} \int_{0}^{t_{1}}\left(\frac{V_{i n} \cdot \sin (100 \pi \cdot t) \cdot k \cdot t_{o n}}{2 \cdot L}\right)^{2} d t\right. \\
&\left.+\frac{1}{0.01} \int_{t_{1}}^{t_{2}}\left(\frac{V_{o} \cdot V_{\text {in }} \cdot \sin (100 \pi \cdot t)-V_{o}}{2 \cdot L \cdot V_{\text {in }} \cdot \sin (100 \pi \cdot t)} \cdot t_{o n}\right)^{2} d t\right)^{1 / 2} . \\
& T H D=\sqrt{\frac{\cos ^{2}(\varphi)}{P F^{2}}-1 .}
\end{aligned}
$$

According to (13)and(14), the corresponding values of $\mathrm{PF}$ and THD with different $k$ at $220 \mathrm{~V}$ and $50 \mathrm{~Hz}$ AC input level are shown in Table I. The trend of PF and THD versus $k$ is shown in Fig. 7.

When $k=0$, the PAB converter works as a conventional buck converter. Fig. 7 and Table I demonstrate that with the increase of $k$, PF increases and THD decreases. However, the value of $k$ could not increase without limit in consideration of the distortion of the input current in a relatively large $k$.

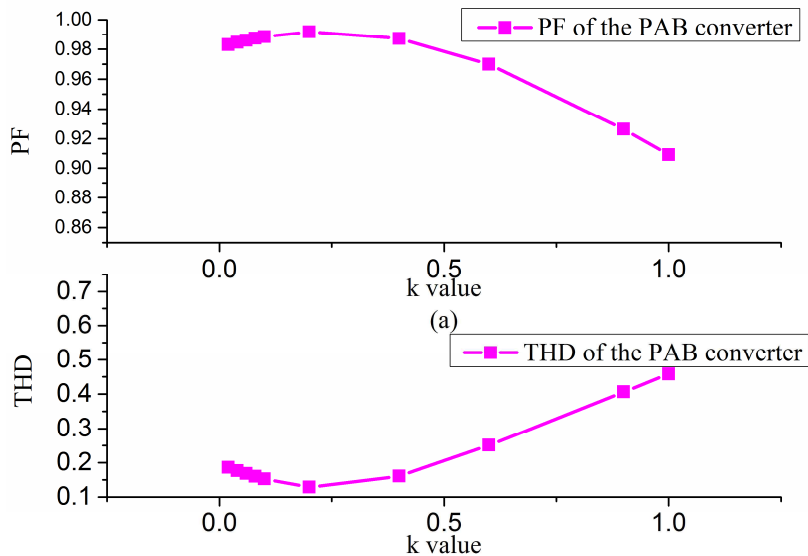

(b)

Fig. 7. (a) Trend of PF versus k. (b) Trend of THD versus k.

TABLE II

\begin{tabular}{cc}
\multicolumn{2}{c}{ RELATIONSHIP BETWEEN $k$ AND $t_{\text {on }}$} \\
\hline \hline$k$ & $t_{\text {on }}(\mu \mathrm{s})$ \\
\hline 0 & 5.13 \\
0.02 & 5.12 \\
0.04 & 5.11 \\
0.06 & 5.10 \\
0.08 & 5.09 \\
0.1 & 5.08 \\
0.4 & 4.94 \\
0.9 & 4.73 \\
\hline \hline
\end{tabular}

The $t_{\mathrm{on}}$ s for different values of $k$ are also included in Table II. $t_{\text {on }}$ decreases gradually with the increase of $k$. In fact, $t_{\text {on }}$ is nearly equal to the $t_{\text {on }}$ of the conventional buck converter only in a case of small values of $k$, that is, below 0.1 .

A small $k$ (i.e., below 0.1 ) is a good choice to preserve the superiority of the buck converter and to consider some factors, such as PF and THD.

In this paper, $t_{\mathrm{on}}$ has a one-to-one correspondence with $k$. Thus, these two variables can be used as one constraint condition. According to the function $D_{0}{ }^{2} / f_{\mathrm{s}}=k^{*} t_{\mathrm{on}}, D_{0}$ and $f_{\mathrm{s}}$ are two independent parameters. Moreover, if one of them must be ensured, another must be known. For small $k$, we assume that the value of $t_{\mathrm{on}}$ is equal to that of the conventional buck converter according to the preceding analysis. For the buck converter without PAB technology, we can obtain the switching frequency function as follows:

$$
\begin{aligned}
f_{s} & =\frac{1}{t_{o n}+t_{o f f}} . \\
t_{o f f} & =\frac{i_{p k, B C M} \cdot L}{V_{o}} .
\end{aligned}
$$

where

$$
P_{o}=\eta \cdot \int_{t_{1}}^{0.005} \frac{V_{o} \cdot\left(V_{i n} \cdot \sin (100 \pi \cdot t)-V_{o}\right) \cdot t_{o n}}{\pi \cdot L} d t .
$$

Thus, 


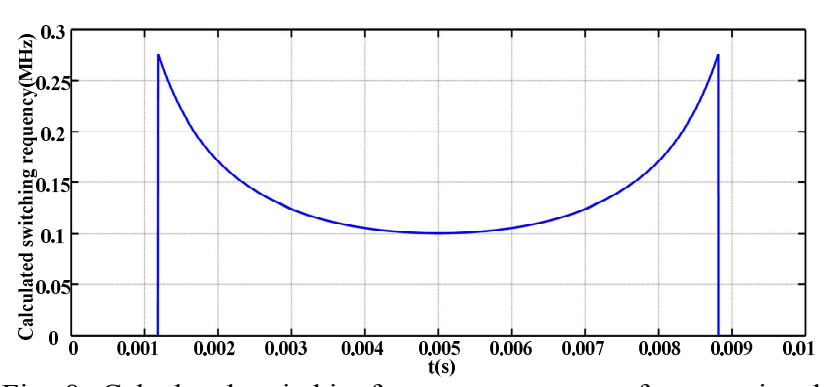

Fig. 8. Calculated switchingfrequency versus $t$ of conventional buck converter.

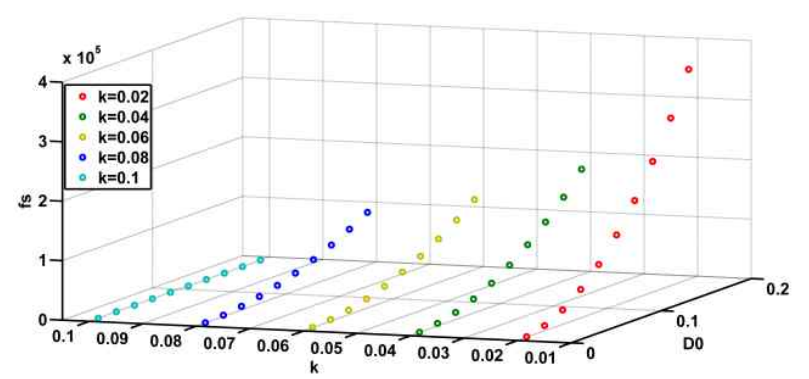

Fig. 9. Relationship between $f_{\mathrm{s}}$ and $\mathrm{k}, D_{0}$ at $220 \mathrm{~V}$ AC input.

$$
\begin{aligned}
f_{s} & =\frac{1}{t_{\text {on }}+t_{\text {off }}} \\
& =\frac{1}{t_{\text {on }}+\frac{\left(V_{\text {in }} \cdot \sin (100 \pi \cdot t)-V_{o}\right)}{V_{o}} \cdot t_{o n}} \\
& =\frac{V_{o}}{t_{\text {on }} \cdot V_{\text {in }} \cdot \sin (100 \pi \cdot t)} .
\end{aligned}
$$

If the output voltage is designed at $80 \mathrm{~V}$, the buck inductance is obtained as $L=150 \mu \mathrm{H}$. Fig. 8 shows the calculated switching frequency versus the function of the phase angle in $220 \mathrm{~V}$ and $50 \mathrm{~Hz} \mathrm{AC}$ input voltage process.

In this paper, $k$ can be used to characterize the power transmission capacity of the circuit. Each value of $k$ may correspond to a specific combination of different $D_{0}$ and $f_{\mathrm{s}}$, as shown in Fig. 9.

The range of operating frequency illustrated in Fig. 8 is approximately $0.1 \mathrm{MHz}$ to $0.27 \mathrm{Mhz}$. Therefore, Fig. 9 does not show the situation where $k$ is greater than 0.1 because when $k$ is greater than $0.1, f_{\mathrm{s}}$ gradually decreases to a value smaller than the minimum value shown in Fig.8.

The selection of $D_{0}$ and $f_{\mathrm{s}}$ must not only meet requirements of the operating frequency of the circuit but also consider the output level of voltage and power. In view of these two factors, the coefficient $k$ is set to 0.08 according to Fig.9, and $f_{\mathrm{s}}$ is set to the lowest frequency $(0.1 \mathrm{Mhz})$ in Fig.8. $D_{0}$ is set to $0.2 \mathrm{as}$ a result of the function $D_{0}{ }^{2} / f_{\mathrm{s}}=\mathrm{k}^{*} t_{\mathrm{on}}$. Then, the validation is based on these values, which proves that this solution is one of the feasible solutions.

\section{RESULTS AND DISCUSSION}

The model derived from the previous section uses a $94 \mathrm{~W}$,

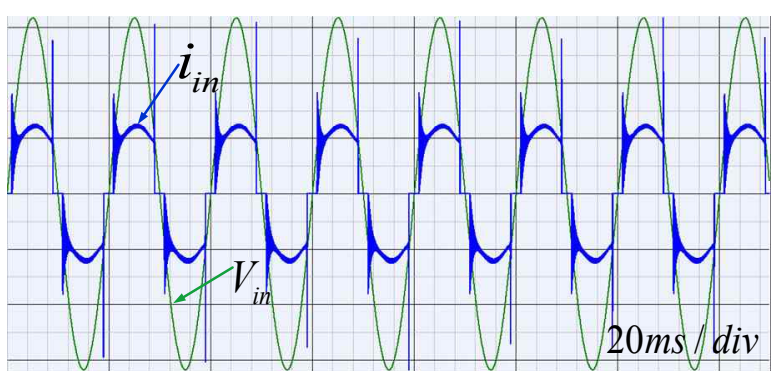

Fig. 10. Input voltage and input current waveforms of the conventional buck PFC converter.

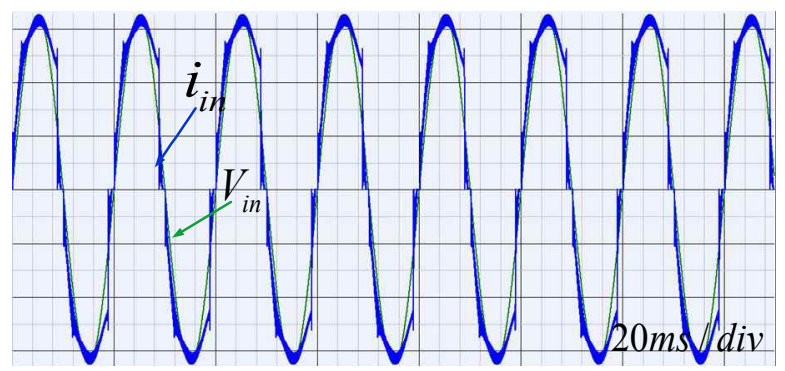

Fig. 11. Input voltage and input current waveforms of the $\mathrm{PAB}$ PFC converter.

TABLE III

PF AND EFFICIENCY FROM 90V INPUT TO 264V AC INPUT OF THE PAB CONVERTER

\begin{tabular}{ccc}
\hline \hline$V_{\text {in }}(\mathrm{V})$ & $\mathrm{PF}(\%)$ & $\eta(\%)$ \\
\hline 90 & 94.19 & 93.16 \\
100 & 97.37 & 93.26 \\
115 & 99.02 & 93.65 \\
132 & 98.18 & 94.12 \\
180 & 98.46 & 95.79 \\
200 & 98.48 & 96.01 \\
230 & 98.31 & 96.12 \\
264 & 98.01 & 96.19 \\
\hline \hline
\end{tabular}

$220 \mathrm{~V}$ AC input, 80V DC output PAB PFC converter as an example. Moreover, the converter can be used as the universal input ( $V_{\text {in }}=90 \mathrm{~V}$ to $264 \mathrm{~V}$ ) front end.

Input voltage and input current waveforms of the conventional buck PFC converter are shown in Fig.10. Input voltage and input current waveforms of the PAB PFC converter are shown in Fig. 11. We can see that the strategy restores the input current during distortion time.

The PF and efficiency from $90 \mathrm{~V}$ input to $264 \mathrm{~V}$ input of the PAB converter are listed in Table III. The buck PFC maintains a high efficiency of approximately $96 \%$ when the input voltage is larger than $115 \mathrm{~V}$. The slight drop of efficiency is the result of the implementation of the control circuit with discrete ICs. Thus far, no dedicated controller IC for the buck PFC is available.

Efficiency versus load at $110 \mathrm{~V}$ AC input and $230 \mathrm{~V}$ AC input is presented in Table IV. Table IV demonstrates that the buck PFC maintains a high efficiency across the load range from $100 \%$ to $25 \%$ of the full load. 
TABLE IV

EFFICIENCY VERSUS LOAD AT 110V AC INPUT AND 230V AC INPUT

\begin{tabular}{ccc}
\hline \hline$P_{\mathrm{o}}(\%)$ & $\eta(\%) @ 110 V_{\mathrm{rms}}$ & $\eta(\%) @ 230 V_{\mathrm{rms}}$ \\
\hline 100 & 93.24 & 96.12 \\
75 & 95.59 & 95.75 \\
50 & 93.39 & 95.16 \\
25 & 91.27 & 94.64 \\
\hline \hline
\end{tabular}

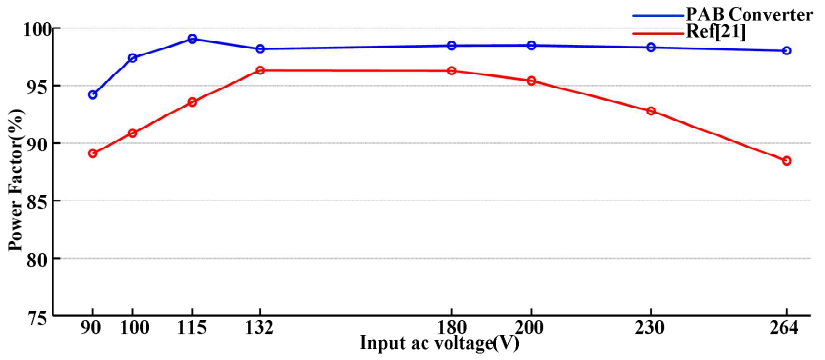

(a)

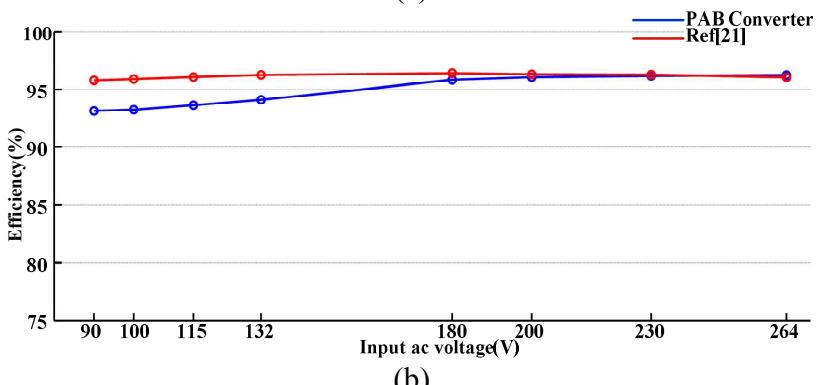

(b)

Fig. 12. (a) Measured PF of PAB converter. (b) Measured efficiency of $\mathrm{PAB}$ converter.

The efficiency and PF of the PAB PFC converter is compared with those of a previously proposed converter of the same type as [21] in Fig. 12. The PAB converter has a higher PF particularly under low input line voltage and high line voltage conditions. Moreover, the efficiency of the PAB converter has a good performance under high input line voltage. The efficiency of the PAB converter is slightly deteriorated compared with that of the prior converter under low input line voltage conditions. The added two diodes and a switch contribute to the total loss.

Fig. 13 shows the THD performance comparison between the PAB PFC converter and the conventional buck converter, which has the same parameters with those of the $\mathrm{PAB}$ converter but without pulse-assisting technique.

To compare with IEC61000-3-2 Class $C$ limits, the vertical axis of Fig. 13 is set as the value of $I_{\mathrm{ac}}(\mathrm{n})$, where $I_{\mathrm{ac}}(\mathrm{n})$ is the n-order harmonic content of the input current $i_{\text {in }}$, and IEC(n) represents the n-order harmonic current limit of IEC61000-3-2 Class C. For example, 110V AC input voltage and $230 \mathrm{~V}$ AC input voltage are needed to represent normal low line and normal high line, respectively. The harmonic performance of the PAB converter meets the IEC61000-3-2 Class $\mathrm{C}$ requirement under both voltages, whereas the conventional buck without pulse-assisting technique cannot

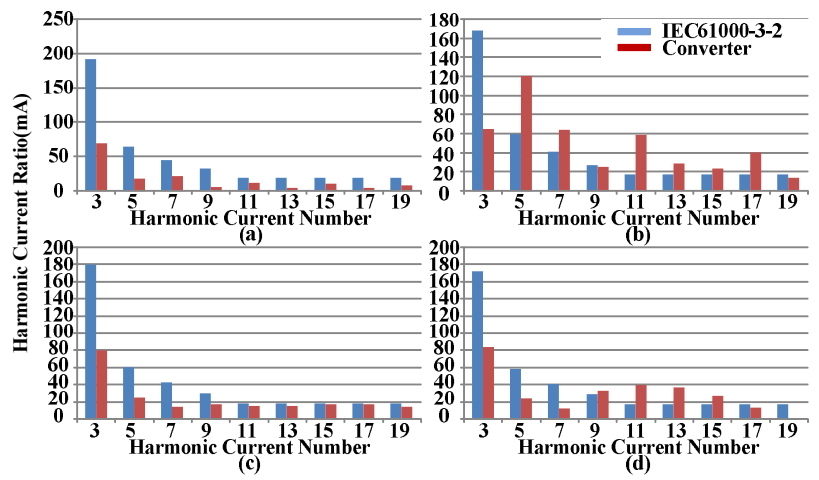

Fig. 13. THD performance comparison between the PAB PFC converter and the conventional buck converter. (a) $I_{\mathrm{ac}}(\mathrm{n})$ compared with IEC(n) of PAB converter at 110VACinput. (b) $I_{\mathrm{ac}}(\mathrm{n})$ compared with IEC(n) of conventional converter at 110VACinput. (c) $I_{\mathrm{ac}}(\mathrm{n})$ compared with IEC(n) of PAB converter at $230 \mathrm{~V}$ AC input. (d) $I_{\mathrm{ac}}(\mathrm{n})$ compared with $\mathrm{IEC}(\mathrm{n})$ of conventional converter at $230 \mathrm{~V}$ AC input.

meet the requirement of both voltages. In addition, the PAB converter performs effectively under normal high line.

\section{CONCLUSION}

According to the design considerations given in the previous sections, a $94 \mathrm{~W}, 80 \mathrm{~V}$ output, universal input ( $V_{\text {in }}=90$ $\mathrm{V}$ to $264 \mathrm{~V}$ ) quasi COT-controlled buck PFC prototype is produced. The IC is based on L6561 with the addition of an oscillator, a voltage subdivision structure, a comparator, and two selectors to control the PAB converter. The improved PF and THD can approach the ideal values compared with the calculated PF and THD under different selections of $k$ factor.

The PAB PFC maintains PF of approximately $98 \%$ at nominal high line and approximately $96 \%$ at nominal low line. In addition, the PAB PFC maintains an efficiency of $98 \%$ at nominal high line and approximately $96 \%$ at nominal low line. The PAB converter achieves high efficiency across a load range from $100 \%$ to $25 \%$ of full load, and the input current harmonics can meet the IEC61000-3-2 Class C standard within the universal input voltage range. In addition, according to the preceding data, the PAB converter performs well at normal high line voltage, but it could meet the requirements at normal low line voltage.

\section{REFERENCES}

[1] M. T. Madigan, R. W. Erickson, and E. H. Ismail, "Integrated high-quality rectifier regulators," IEEE Trans. Ind. Electron., Vol. 46, No. 4, pp. 749-758, Aug. 1999.

[2] G. C. Hsieh, J. F. Tsai, M. F. Lai, and J. C. Li, "Design of power factor corrector for the off line isolated buck/boost converter by a voltage follower technique," in Proc. IEEE IECON'93, pp. 959-964, 1993.

[3] J. S. Glaser and A. F. Witulski, "Design issues for high power factor AC-DC converters systems," in Proc. IEEE PESC'95, pp.542-548, 1995. 
[4] Electromagnetic Compatibility (EMC), Part 3-2: Limits-Limits for Harmonic Current Emissions (Equipment Input Current $\leq 16$ A Per Phase), International Standard IEC 61000-3-2, 2005, 2013.

[5] European Commission, Code of Conduct on Energy Efficiency of External Power Supplies, http://sunbird.jrc.it/energyefficiency/pdf/Workshop_Nov.20 04/PS $\% 20$ meeting/Code $\% 20$ of $\% 20$ Conduct $\% 20$ for $\% 20$ PS \%20Version\%202\%2024\%20November\%202004.pdf,2004.

[6] Environmental Protection Agency (EPA), Energy Star Program Requirements For Single Voltage External $A C-D C$ and $A C-A C$ Power Supplies, http://www.energystar.gov/ia/partners/product_specs/progra m_reqs/EPS_Eligibility_Criteria.pdf, 2008.

[7] G. G. Park, K. Y. Kwon, and T. W. Kim, "PFC dual boost converter based on input voltage estimation for DC inverter air conditioner," Journal of Power Electronics, Vol. 10, No. 3, pp. 293-299, May 2010.

[8] L. Huber, B. T. Irving, and M. M. Jovanovic, "Review and stability analysis of PLL-based interleaving control of DCM/CCM boundary boost PFC converters," IEEE Trans. Power Electron., Vol. 24, No. 8, pp. 1992-1999, Aug. 2009.

[9] L. S. Yang, T. J. Liang, and J. F. Chen, "Analysis and design of a novel, single-stage, three-phase AC/DC step-down converter with electrical isolation," IET Power Electron., Vol. 1, No. 1, pp. 154-163, Mar. 2008.

[10] V. F. Pires and J. F. Silva, "Single-stage double-buck topologies with high power factor," Journal of Power Electronics, Vol. 11, No. 5, pp. 655-661, Sep. 2011.

[11] J. Duarte, L. R. Lima, and L. Oliveira, "Single-stage high power factor step-up/step-down isolated AC/DC converter," IET Power Electron., Vol. 5, No. 8, pp. 1351-1358, Sep. 2012.

[12] B. Singh and G. D. Chaturvedi, "Analysis, design and development of a single switch flyback buck-boost AC-DC converter for low power battery charging applications," Journal of Power Electronics, Vol. 7, No. 4, pp. 318-327, Oct. 2007.

[13] B. Singh and G. D. Chaturvedi, "analysis, design, modeling, simulation and development of single-switch AC-DC converters for power factor and efficiency improvement," Journal of Power Electronics, Vol. 8, No. 1, pp. 51-59, Jan. 2008.

[14] V. Grigore and J. Kyyra, "High power factor rectifier based on buck converter operating in discontinuous capacitor voltage mode," IEEE Trans. Power Electron., Vol. 15, No. 6, pp. 1241-1249, Nov. 2000.

[15] J.H. Park and B. H. Cho, "The zero voltage switching (ZVS) critical conduction mode (CRM) buck converter with tapped-inductor," IEEE Trans. Power Electron., Vol. 20, No. 4, pp. 762-774, Jul. 2005.

[16] W. W. Weaver and P. T. Krein, "Analysis and applications of a current sourced buck converter," in Proc. IEEE Appl. Power Electron. Conf. (APEC), pp. 1664-1670, Feb. 2007.

[17] Y. Chen, Y. Nan, and Q. Kong, "A loss-adaptive self-oscillating buck converter for LED driving," IEEE Trans. Power Electron., Vol. 7, No. 10, pp. 4321-4328, Oct. 2012.
[18] G. Spiazzi and S. Buso, "Power factor preregulators based on combined buck-flyback topologies," Power Electronics, IEEE Trans. Power Electron., Vol. 15, No. 2, pp. 197-204, 2000.

[19] H. Choi, "Interleaved boundary conduction mode (BCM) buck power factor correction (PFC) converter," IEEE Trans. Power Electron., Vol. 28, No. 6, pp. 2629-2634, 2013.

[20] K. Fung, W. H. Ki, and P. K. T. Mok, "Analysis and Measurement of DCM Power Factor Correctors," in Proc. IEEE Power Electronics Specialists Conference, pp. 709-714, 1999.

[21] L. Huber, L. Gang, and M. M. Jovanovi'c, "Design-oriented analysis and performance evaluation of buck PFC front end," IEEE Trans. Power Electron., Vol. 25, No. 1, pp. 85-94, Jan. 2010.

[22] H. Endo, T. Yamashita, and T. Sugiura, "A high power factor buck converter," in Proc. IEEE Power Electron. Spec. Conf. (PESC), pp. 1071-107, Jun./Jul. 1992.

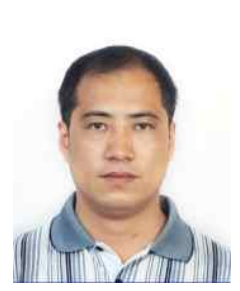

Jiangtao Xu was born in 1979 in Hebei, P. R. China. He received his M.S. and Ph.D degrees in Microelectronics and Solid State Electronics in Tianjin University from Tianjin University in 2004and 2007, respectively. $\mathrm{He}$ is currently an associate professor in the School of Electronic Information Engineering, Tianjin University, P. R. China. He is an IEEE member. His research interests include power management ICs and system, image sensors ICs, and system.

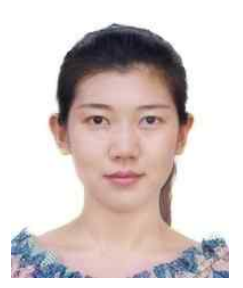

Meng Zhu was born in Tianjin in 1988,P. R. China. She received her B.S. degree in electronic science and technology from Beijing Jiaotong University, Beijing, China, in 2011. She is currently working toward her M.S. degree in Microelectronics and Solid State Electronics in Tianjin University, P. R. China. Her research interests include power factor correction IC design, power management, power converter, and analog ICs.

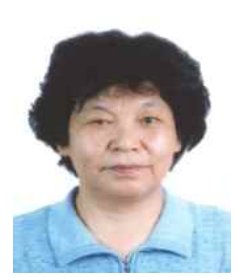

Suying Yao was born in 1947 in Hebei, P. R. China. She is a professor in the School of Electronic Information Engineering, Tianjin University. Her research interests include power management ICs and system and image sensor ICs and system. 